\title{
Preoperative localization of a gastrin-secreting tumour by total body imaging with ${ }^{111}$ Indium-labelled pentatreotide
}

Humera Ali mD, Aaron Hendler mD frCpC, Bryce TAylor md frCsc, STEPHEN WOlman md frCpC

H Ali, A HENDLER, B TAYLOR, S WOLMAN. Preoperative localization of a gastrin-secreting tumour by total body imaging with ${ }^{111}$ Indium-labelled pentatreotide. Can J Gastroenterol 1994;8(3):189-192. A 41-year-old female presented with persistent diarrhea, and was diagnosed with Zollinger-Ellison syndrome when her gastrin level was greater than $3000 \mathrm{ng} / \mathrm{L}$. All modalities for preoperative localization of her gastrinoma were unsuccessful, including transabdominal and endoscopic ultrasound, computed tomography, pancreatic angiogram, selective transhepatic portal venous sampling and magnetic resonance imaging. The gastrin-secreting tumour was visualized using the somatostatin analogue pentatreotide labelled with ${ }^{111}$ Indium, combined with gamma camera imaging. A successful resection of the tumour resulted in the normalization of serum gastrin levels 3.5 years after presentation. A discussion of the merits and sensitivities of these tests for preoperative localization of gastrin-secreting tumours will be presented.

Key Words: Gastrinoma, ${ }^{111}$ Indium-pentatreotide, Neuroendocrine tumours, Somatostatin receptor imaging

Localisation pré-opératoire d'une tumeur sécrétrice de gastrine à l'aide de l'imagerie totale au moyen de penta-tréotide marqué à $1^{111}$ indium

RÉSUMÉ : Une femme de 41 ans présentant de la diarrhée persistante a reçu un diagnostic de syndrome de Zollinger-Ellison lorsque son taux de gastrine s'est révélé supérieur à $3000 \mathrm{ng} / \mathrm{L}$. Toutes les modalités de localisation préopératoire de son gastrinome ont échoué, y compris l'échographie trans-abdominale et endoscopique, la tomographie assistée par ordinateur, l'angiographie pancréatique, le prélèvement d'un échantillon veineux portal transhépatique sélectif et

\section{continued on next page}

Departments of Medicine, Radiology, Surgery and Gastroenterology, University of Toronto, Toronto, Ontario

Correspondence and reprints: Dr Stephen Wolman, The Toronto Hospital, 200 Elizabeth Street, Room 220, 9 th floor, Eaton Wing, General Division, Toronto, Ontario M5G 2C4. Telephone (416) 340-3507

Received for publication August 6, 1993. Accepted August 25, 1993
Dreoperative localization of 1 gastrinomas followed by surgical resection is the procedure of choice for gastrin-secreting tumours. Current imaging techniques, including ultrasound, computed tomographic scan, angiography and selective venous sampling, identify only $50 \%$ of tumour sites (1). Endoscopic ultrasound has recently become popular, but its sensitivity is limited to pancreatic and lumenal sites. ${ }^{111}$ Indium-pentatreotide, a radiolabelled somatostatin analogue, can be used to perform total body scanning for primary and metastatic sites of neuroendocrine tumours expressing somatostatin receptors such as gastrinomas. This noninvasive imaging method should be considered after computed tomography and ultrasound fail to locate the tumour.

\section{CASE PRESENTATION}

A 41-year-old female presented to a gastroenterologist five months after the onset of progressively worsening diarrhea. She had a perianal fistula and inguinal hernia repair within the past few months and had been on antibiotics. Diarrhea consisted of 12 watery, nonbloody bowel movements per day. There was urgency but no tenesmus, and mild abdominal cramping was relieved by bowel movements. Avoid- 
l'imagerie par résonance magnétique. La tumeur sécrétrice de gastrine a été visualisée à l'aide de l'analogue de la somatostatine pentatréotide marqué à $1^{111}$ indium, combinée avec une imagerie par caméra gamma. Le succès de la résection de la tumeur a entraîné la normalisation des taux de gastrine sérique 3,5 ans après l'apparition du tableau. Une discussion des avantages et des sensibilités de ces épreuves pour la localisation préopératoire des tumeurs sécrétrices de gastrine sera présentée.

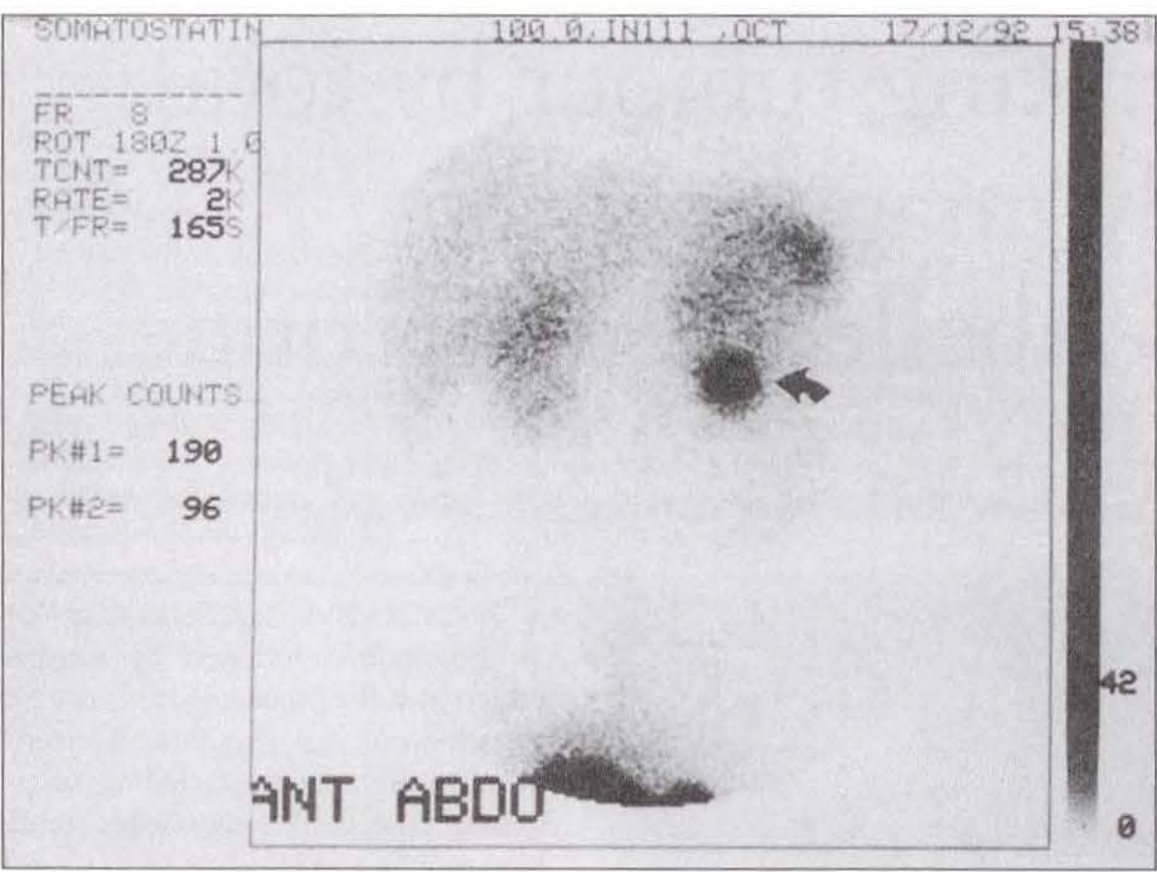

Figure 1) Planar muclear scan image of ${ }^{111}$ Indium-pentatreotide-labelled gastrinoma $4 \mathrm{~h}$ after injection. The gastrinoma is indicated by an arrow

ance of dairy products provided no relief of symptoms. There was no travel history, fevers or sweats. Despite her illness, the patient's appetite remained good. Physical examination was unremarkable with stable vital signs and no postural changes.

Investigations revealed stool samples were negative for culture, Clostridium difficile toxin and white blood cells. Colonoscopy was completely normal to the cecum. Gastroscopy showed a normal esophagus, but moderate to severe gastritis in the antrum and severe duodenitis. The patient was prescribed misoprostol $200 \mu \mathrm{g}$ qid and diphenoxylate. Two months later, she continued to have symptoms and was referred to the authors' centre for further investigation. At referral the patient had experienced a weight loss of $6.8 \mathrm{~kg}$. Further history revealed diarrhea occurred despite a diet of clear fluids or fasting in preparation for endoscopic investiga- tions. Stool volumes were 1.6 to 2.0 $\mathrm{L}$ in 24 h collections.

Investigations revealed the following data. Red blood cell folate and vitamin $B_{12}$ levels were normal. A bile acid breath test was negative. Iron, ionized calcium, carotene, urine vanillylmandelic acid and 5-hydroxyindoleacetic acid, prolactin, growth hormone, intact parathyroid hormone and morning cortisol levels were all normal. Calcitonin was less than $8 \mathrm{pmol} / \mathrm{L}$ (normal less than 15). The patient's gastrin level, however, was $3150 \mathrm{ng} / \mathrm{L}$ (normal less than 90). A diagnosis of Zollinger-Ellison syndrome was made. The patient was treated for symptoms, successfully at first, with omeprazole $20 \mathrm{mg}$ bid; somatostatin $200 \mu \mathrm{g}$ tid was added when the diarrhea returned, but this did not produce any change in the diarrhea. Later the patient required as much as omeprazole $80 \mathrm{mg}$ bid to control the diarrhea.
Imaging studies were initiated to locate a gastrinoma. Computed tomography of abdomen, chest $x$-ray and ultrasound were performed in duplicate and were read as negative for mass lesions. Repeat gastroscopy (seven months after the first) showed scattered erosive hemorrhagic areas in the stomach and duodenum, with enlarged folds and rugae consistent with a gastrin hypersecretory state. Pancreatic angiogram failed to reveal any tumour. Transhepatic portal venous sampling did not provide meaningful data which could have located a tumour. Magnetic resonance imaging did not show any mass lesions. Repeat gastrin level testing (two years after the first) was $2374 \mathrm{ng} / \mathrm{L}$. Repeat gastroscopy showed normal mucosa except for prominent rugae.

Based on reports in the literature, an attempt was made by the radiopharmacy in the authors' hospital to attach a radioiodine label to commercially available octreotide $(2,3)$. This was not successful because of inadequate binding of the radiolabel.

Recently, an indium-labelled somatostatin analogue - ${ }^{111}$ Indium-pentatreotide (octreoscan 111, Malinckrodt) - was made available for investigational use. A request made by the authors to the Health Protection Branch for emergency release of the compound was granted. The patient was given an intravenous injection of pentatreotide reconstituted with 12.3 $\mathrm{mBq}{ }^{111}$ Indium-chloride.

Both whole body planar (Figure 1) and single photon emission computed tomography (SPECT) images of the $a b$ domen (Figure 2) were obtained with an Elscint gamma camera (Haifa, Israel) at $4 \mathrm{~h}$, and planar images alone were obtained at $24 \mathrm{~h}$. The images demonstrated an intense focus of abnormal activity anterior to the lower pole of the kidney, and the abnormality reportedly was located either in the tail of the pancreas or nearby.

Based on the ${ }^{111}$ Indium-pentatreotide scan, the patient was taken to laparotomy. Intraoperative ultrasound confirmed that the mass was in the small bowel mesentery, not the pancreas. There was no evidence of another primary site. A $3 \mathrm{~cm}$ mass was 
resected and pathologically confirmed as a gastrinoma. Follow-up gastrin levels, one and two months after surgery, were 80 and $56 \mathrm{ng} / \mathrm{L}$, respectively. The patient is no longer on medications, and is asymptomatic. Her gastrin levels will be followed every three months for the first year.

\section{DISCUSSION}

Somatostatin inhibits secretion in various neuroendocrine tissues, in addition to its likely role as a neurotransmitter. Tumours from cells naturally containing somatostatin receptors often continue to express varying concentrations of somatostatin receptors, such as pituitary and islet cell tumours. In addition, some tumours not naturally containing somatostatin receptors may also occasionally do so, no doubt as part of malignant transformation. Examples of these are meningiomas and breast carcinomas (4). Somatostatin administered as therapy may relieve symptoms of tumour hypersecretion, and it has been shown to inhibit tumour growth $(5,6)$.

Gastrinomas are often difficult to localize by conventional techniques if they are less than $2 \mathrm{~cm}$ in size - unfortunately they often are smaller (7), and only $50 \%$ of tumours are found with commonly used imaging procedures (8). Since tumours are difficult to find, and patients are being treated with more potent acid-inhibiting pharmaceutical formulations $\left(\mathrm{H}_{2}\right.$ blockers, proton pump inhibitors), patients are presenting later with metastatic disease more often than they are with ulcer complications (1). Sixty per cent of gastrinomas are malignant, and metastatic gastrinoma carries a 20 to $40 \%$ five-year survival $(1,9,10)$. Therefore, although symptomatic control has improved, tumour localization for resection before progression to metastatic disease is still vital. The mortality associated with metastases is high and patients often go on to an exploratory laparotomy despite a lack of localizing information provided by conventional investigation. Intraoperative ultrasound combined with palpation improves the sensitivity of finding the tumour (11), yet $40 \%$ of gastrinomas

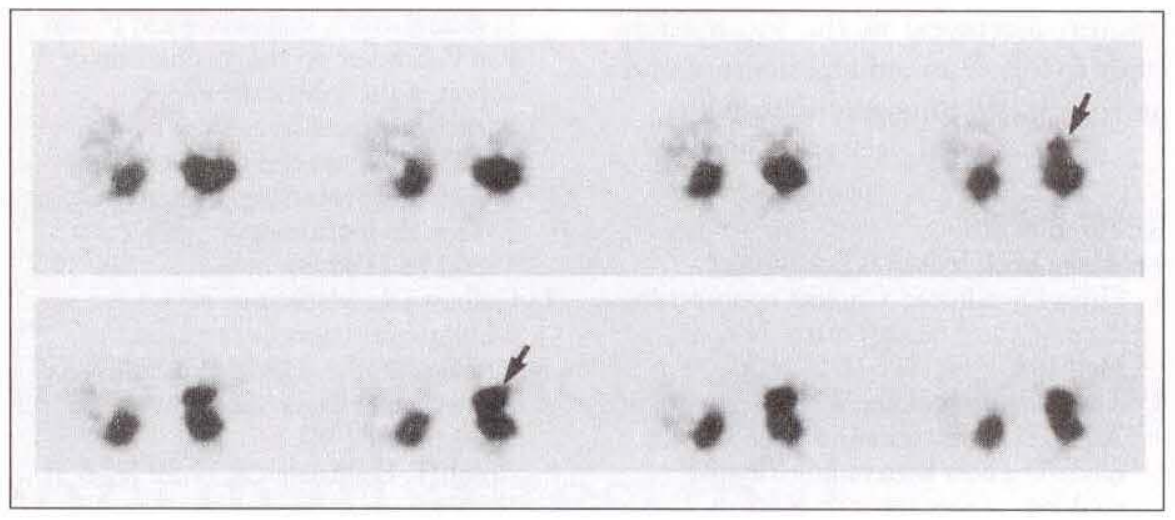

Figure 2) Transaxial single photon emission computed tomography (SPECT) images of the gastrinoma using "Indium-pentatreotide. The tumour (arrow) is localized anterior to the lower pole of the left kidney

are still not found at laparotomy $(12,13)$.

In the past 20 years, a number of imaging techniques have tried to localize gastrinomas preoperatively. Initially abdominal ultrasound and computed tomography were employed, but their sensitivity relates to tumour size. In one study looking at islet cell tumours ranging in size from 0.7 to $2.0 \mathrm{~cm}$, computed tomography visualized seven of $16 \mathrm{tu}$ mours, and ultrasound nine of 15 . Sensitivity decreased with tumours in the tail of the pancreas (14). In another study, the sensitivity of ultrasound to detect extrahepatic gastrinomas was $20 \%$ and that of computed tomography was $45 \%$ (15). Magnetic resonance imaging is even less sensitive than ultrasound and computed tomography (15). If the tumour is not localized, pancreatic angiography and transhepatic selective venous sampling have been advocated. More recently, endoscopic ultrasound has shown promise. Its sensitivity exceeds that of angiography. Rosch's study (4) in 1992 showed that $82 \%$ of pancreatic neuroendocrine tumours not found by conventional ultrasound and computed tomography were localized by endoscopic ultrasound. Angiography can localize tumours 30 to $40 \%$ of the time $(1,8)$. Transhepatic venous sampling has a 70 to $90 \%$ sensitivity, but only for tumours in the duodenum or pancreas (16). Furthermore, the correlation between hormone gradient and tumour localization, eg, head versus tail of pancreas, has a sensitivity of $35 \%$.
The ${ }^{111}$ Indium-pentatreotide scan has the potential of a noninvasive method to localize tumours and provides the advantage of picking up metastatic disease in tumours containing somatostatin receptors $(2,3)$. It appears that growth hormone pituitary adenomas, meningiomas, carcinoid tumours, gastrinomas, and some cases of breast carcinomas and insulinomas are most likely to contain somatostatin receptors $(2,4)$. Of these, gastrinomas can be extrapancreatic 30 to $40 \%$ of the time $(8,13,17)$. Duodenal and gastric sites may be visualized by experienced endoscopists with ultrasound. However, peripancreatic and periduodenal lymph nodes may be more difficult to locate.

\section{CONCLUSIONS}

Since the expertise for this procedure is not yet readily available, the ${ }^{111}$ Indium-pentatreotide scan combines the advantages of localizing tumours far from the endoscopist's and angiographer's view with an easily administered and noninvasive test in a nuclear medicine facility. In Lamberts' study (3), seven of nine pancreatic endocrine tumours were visualized. Larger studies are needed to evaluate sensitivity and specificity for this procedure. Nevertheless, because it is noninvasive and can scan the whole body, this technique provides significant advantages over other investigative methods. We conclude that ${ }^{111}$ Indium-pentatreotide imaging should be considered for gastrinomas (or any tumour expressing soma- 
tostatin receptors) as the localization study to follow an unhelpful ultrasound and computed tomography scan.

\section{REFERENCES}

1. Wolfe MM, Jensen RT. Zollinger Ellison Syndrome. Current concepts in diagnosis and management. $\mathrm{N}$ Engl J Med 1987;317:1200-9.

2. Krenning EP, Bakker WH, Breeman WAP, et al. Localization of endocrine related tumors with radioiodinated analogue of somatostatin. Lancet 1989;1:242-4.

3. Lamberts SWJ, Bakker WH, Reubi JC, Krenning EP. Somatostatin-receptor imaging in the localization of endocrine tumors. N Engl J Med 1990;323:1246-9.

4. Reubi JC, Maurer R, von Werder K, Torhorst J, Klijn JGM, Lamberts SWJ. Somatostatin receptors in human endocrine tumors. Cancer Res 1987;47:5758-64.

5. Reubi JC. A somatostatin analog inhibits chondrosarcoma and insulinoma tumor growth. Acta Endocrinol 1985;109:108-14.

6. Lamberts SWJ, Reubi JC, Uitterlinden
$\mathrm{P}$, Zuiderwijk J, van den Werff $\mathrm{P}$, van Hal P. Studies on the mechanism of action of the inhibitory effect of the somatostatin analog SMS201-995 on the growth of the PRL/ACTH secreting pituitary tumor 7315 a. Endocrinology 1986;118:2188-94.

7. Galbert DL, Markowitz AM. Insulinoma: diagnosis, surgical management and long-term follow-up. Review of 41 cases. Am J Surg 1980;139:682-90.

8. Rosch T, Lightdale CJ, Botet JF, et al. Localization of pancreatic endocrine tumors by endoscopic ultrasonography. N Engl J Med 1992;326:1721-6.

9. Wolfe MM, Alexander RW, McGuigan JE. Extrapancreatic, extraintestinal gastrinoma: effective treatment by surgery. N Engl J Med 1982;306:1533-6.

10. Zollinger RM, Ellison EC, Fabri PJ, Johnson J, Sparks J, Carey LC. Primary peptic ulcerations of the jejunum associated with islet cell tumors: twenty five year appraisal. Ann Surg 1980;192:422-30.

11. Frucht H, Norton JA, London JF, et al. Detection of duodenal gastrinomas by operative endoscopic transillumination. A prospective study. Gastroenterology 1990;99:1622-7.

12. Stefanini P, Carboni M, Patrassi N, Basoli A. Beta-islet cell tumors of the pancreas: results of a study on 1067 cases. Surgery 1974;75:597-609.

13. Norton JA, Collen MJ, Gardner JD, et al. Prospective study of gastrinoma localization and resection in patients with Zollinger-Ellison syndrome. Ann Surg 1986;204:468-79.

14. Gunther RW, Klose KJ, Ruckert K, et al. Islet cell tumors: detection of small lesions with computed tomography and ultrasound. Radiology 1983;148:485-8.

15. Frucht H, Doppman JL, Norton JA, et al. Gastrinomas: comparison of MR imaging with CT, angiography, and ultrasound. Radiology 1989;171:713-7.

16. Vinik AI, Moattari AR, Cho K, Thompson N. Transhepatic portal vein catheterization for localization of sporadic and MEN gastrinomas: a ten year experience. Surgery 1990;107:246-55.

17. Ellison EH, Wilson SD. The Zollinger-Ellison syndrome: re-appraisal and evaluation of 260 registered cases. Ann Surg 1964;160:512-30. 


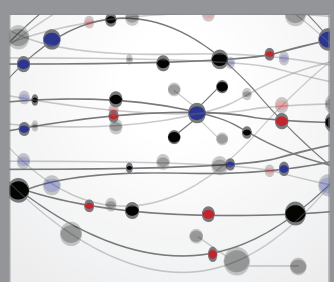

The Scientific World Journal
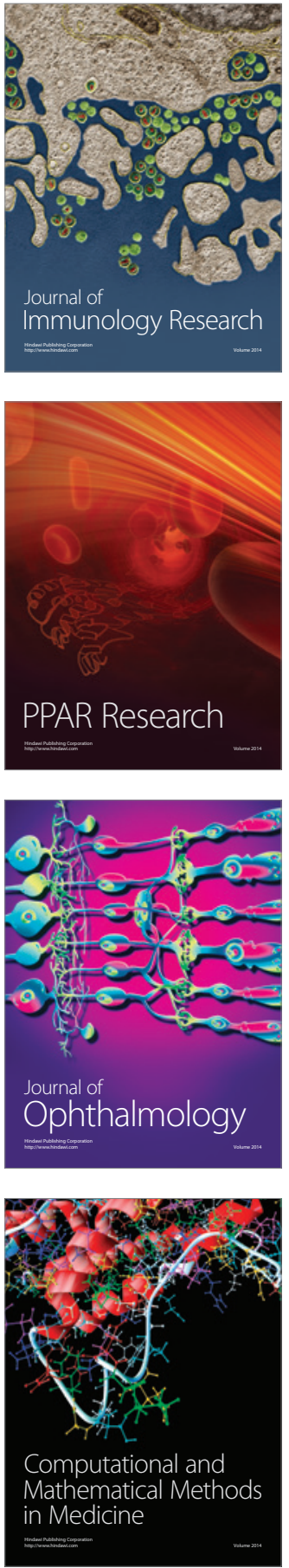

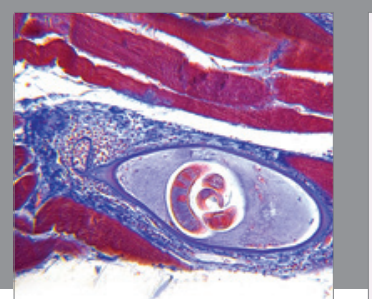

Gastroenterology Research and Practice

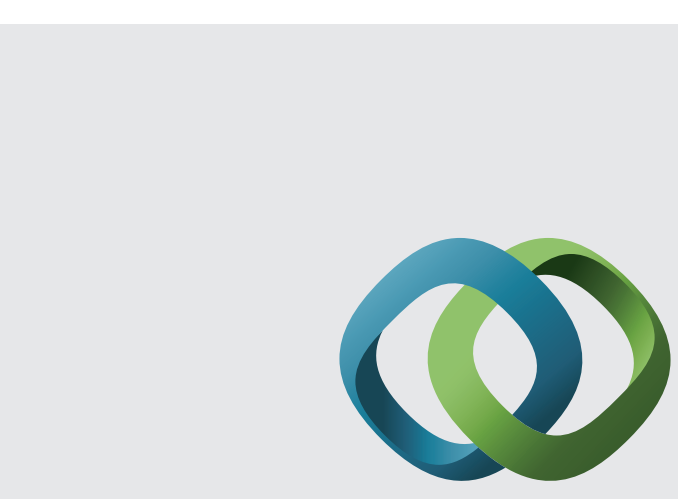

\section{Hindawi}

Submit your manuscripts at

http://www.hindawi.com
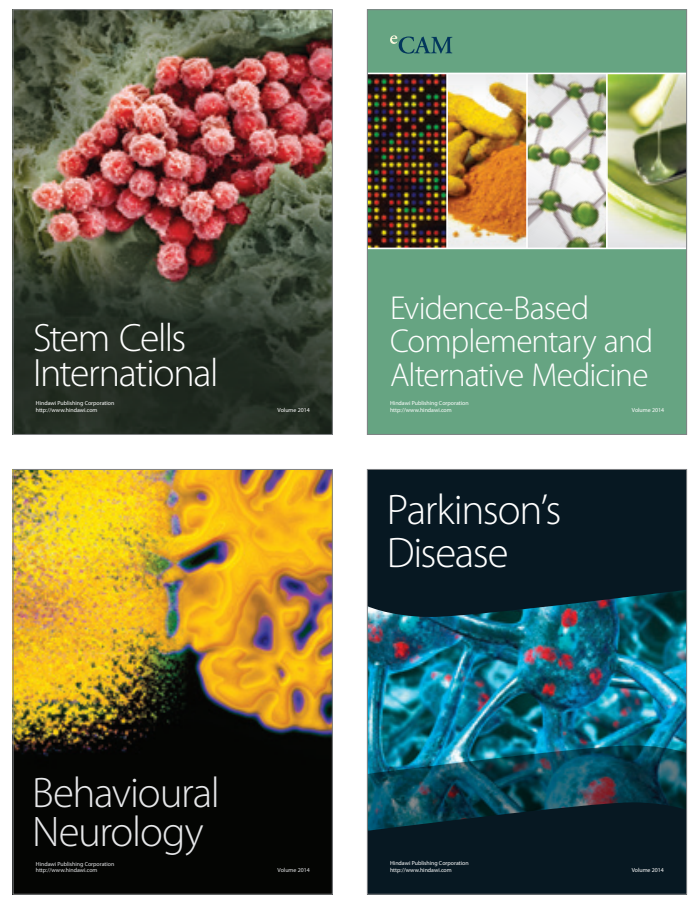
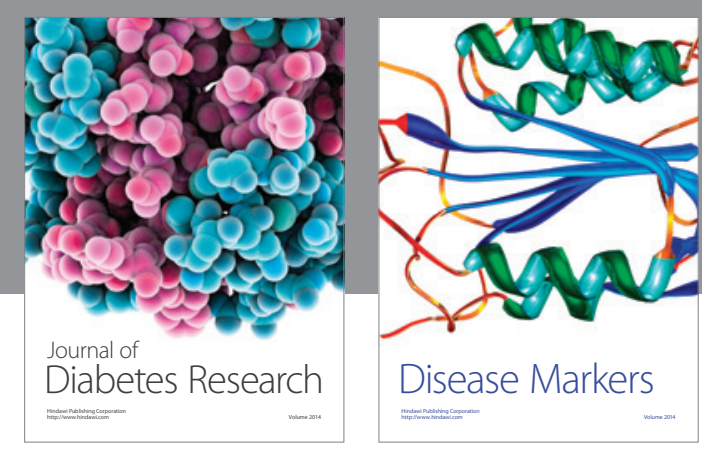

Disease Markers
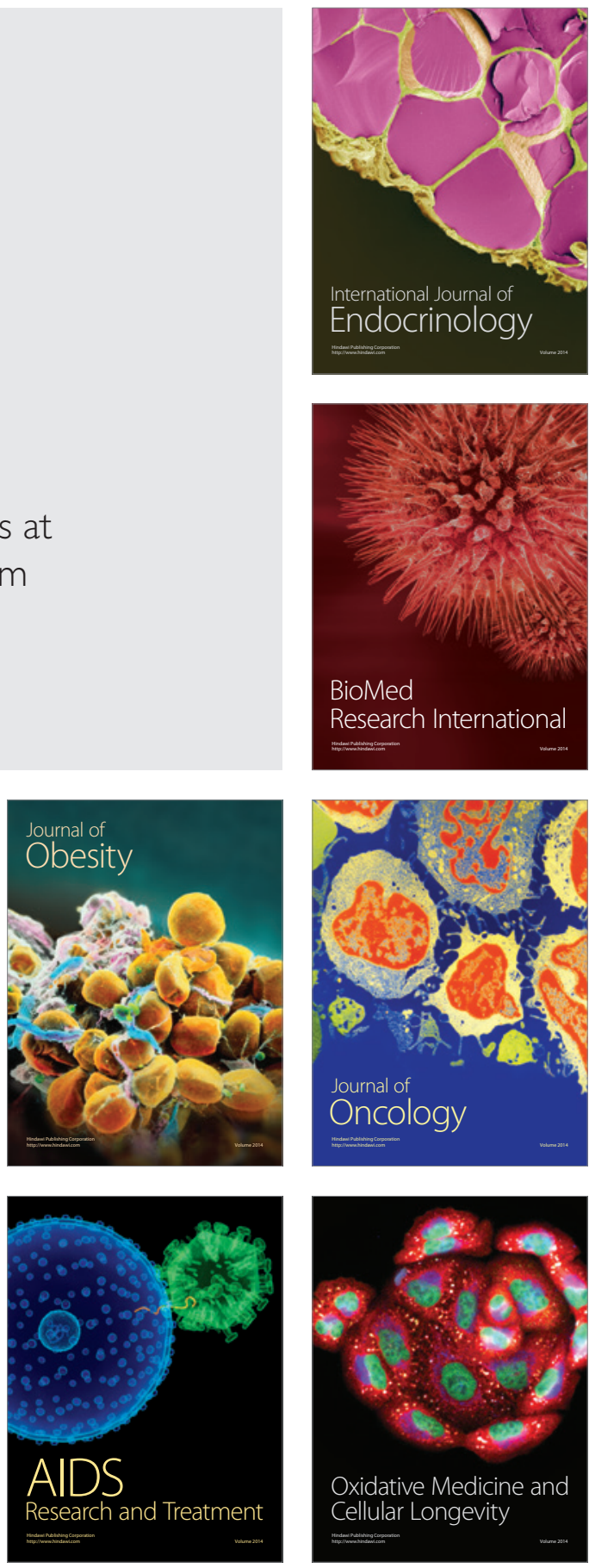